\title{
Perception of Virtual Class during the Covid-19 Pandemic: A Case Study of Tribhuvan University
}

Deo Narayan Yadav*

\begin{abstract}
Assessing acceptance level of virtual classroom technology has become important at the Tribhuvan university after Covid-19 pandemic. This article has investigated the acceptance level of virtual classroom from teachers and students involved in BIT course delivery and previous experiences of virtual classroom from various research articles. The assessment framework is based on the setting of virtual classroom at Patan Multiple Campus (PMC) immediately after the COVID-19 pandemic lockdown using "Office 365 Al education free version of MS Teams" in pmc.edu.np domain and Moodle-Open-source learning platform. The BIT courses were delivered through virtual classrooms, which were accessed by both students and teachers. The conclusion of the study is that the use of virtual classroom as an alternative mode of course delivery is accepted by teachers and students, but with different levels of acceptance. The study focuses on students and teachers involved in one particular BIT classes and it needs to further research in other course domain and in larger scale. This paper provides information that will be the interest of Tribhuvan University in implementing virtual classroom as an alternate mode of course delivery.
\end{abstract}

Key words: Virtual classroom, higher education, acceptance, virtual technology \& pedagogy.

\section{Introduction}

The COVID 19 pandemic has led schools and universities to shut all across the world. Worldwide students are affected by universities closures and are not able to attend the classroom due to the pandemic. As a result, education has changed dramatically, with the distinctive rise of online learning, whereby teaching is undertaken remotely and on digital platforms. With this sudden shift away from the classroom in many parts of the globe,

${ }^{*}$ Mr. Yadav is an Associate Professor in the Department of Computer Science and Information Technology and Coordinator of the Bachelor in Information Technology (BIT) Program at Patan Multiple Campus.Email:deo494685@hotmail.com 
some are wondering whether the adoption of online learning will continue to persist postpandemic, and how such a shift would impact the worldwide education system. There has been a significant surge in usage of virtual tutoring, video conferencing tools, or online learning software since COVID-19 and it is incumbent upon all of us to explore its full potential (Li Cathy et al., 2020).

The effect of COVID-19 in Nepal's schools and universities is not different from the world and has affected largely the education system of our country too. Although it is too early to judge how reactions to COVID-19 will affect the education systems in Nepal, there are signs suggesting that it could have a lasting impact on the trajectory of learning innovation and digitization. For this, Tribhuvan University has decided MS Teams virtual classroom platform as an alternate mode of course delivery. TU has also developed two guidelines "Virtual Class Management Guidelines-2077" and "Online Class Operation Guidelines-2077" based on "Guidelines for Facilitating Alternative Mode of Learning in Higher Education-2077" from University Grants Commission Nepal. The virtual classroom is an internet-based technology that is used as a medium of interaction between teachers and students in learning and teaching activities. Based on the aforementioned information, the research questions were asked for this research purpose. The results of this study are intended to edify policymakers, administrators, teachers and students on implementation and management of virtual classroom.

\section{Methods and Materials}

The main objective of this research study is to access the acceptance level of virtual classroom compared to traditional face-to-face classroom for higher education at the Patan Multiple Campus, Tribhuvan University.

The study begin with a review of extensive literature on best practices in online education, focusing on various online educational technologies used for course delivery of higher education. The strategy for conducting this literature review was to use keywords such as virtual classroom, online virtual class technologies for higher education, viability of virtual classroom, factors for effective e-learning integration in higher education, virtual classroom pedagogy, student performance in an online vs. face-to-face. These keywords were then searched through education, literature databases, websites and repository of the Tribhuvan University. Research based articles, reports related to virtual classroom and focused on e-learning integration in higher education were also searched. 
Moreover, a sample survey was also carried out from teacher and student who have been involved in virtual classroom in BIT course to explore and assess the educational experience in the virtual classes and assess their views about virtual classroom in BIT course delivery at PMC. Finally, three simple questions were asked to assess acceptance level of virtual classroom in offering the BIT online course delivery.

\section{Participants}

The study sample consists 44 teachers and students who participated in the online course delivered through Microsoft Teams, a virtual classroom technology in this case. Of the 44 total participants, 36 were students while 8 were teachers. The research questions were focused on accessing the acceptance level and their views about the virtual classroom in online course delivery in higher education at PMC, Tribhuvan university. Participants were selected from Patan Multiple Campus and BIT students and teachers only. This is considered a limitation of the study. No special preferences or weights were given to student and teacher. Each student was considered a single, discrete entity or statistic. This study does not differentiate between part-time and full-time teachers and students were selected from BIT courses. Therefore, computer literate or skilled students have been included in this study.

\section{Test Instruments}

The study uses the "Microsoft Forms" in-built within MS Teams to conduct a survey, quiz, and poll to determine teacher and student opinions about the virtual classroom. Based on the research questions, forms were created and sent to the teachers and students for the feedback. The collected responses from the students are grouped and summarized in the result section.

\section{Data Collection Procedures}

The teacher's and student's response were analysed and processed using MS excel to draw chart and calculate specific values. These converted values were subsequently used to draw conclusions that are presented in the following sections.

\section{Literature Review and Conceptual Framework}

This chapter provides a review of literature related to virtual classroom and its technologies. In the literature review, a comprehensive review of previous article, studies on virtual classroom and expert views on implementation of virtual classroom after covid-19 are 
presented. Exploration of previous studies in the area helps to focus the study and provides an insight in terms of current status of virtual classroom implementation in education.

Before assessing acceptance level of virtual classroom are raised, a review is presented below in order to provide the context of the research report.

$>$ Expert Views about online virtual classroom after covid-2019 pandemic

$>$ Concept of virtual classroom.

$>$ Virtual classroom technologies (MS Teams Features)

$>$ What is pedagogy?

\section{Expert Views on Virtual Classroom after Covid-19 pandemic}

The COVID-19 pandemic has changed the dynamics across the world, including the education sector. Physical classrooms were replaced by virtual classroom. Even before COVID-19, there was already high growth and adoption in education technology (Li Cathy et al., 2020).

Resilience must be built into our educational systems. The rapid spread of COVID-19 has demonstrated the importance of building resilience to face various threats, from pandemic disease to extremist violence to climate insecurity, and even, yes, rapid technological change. The pandemic is also an opportunity to remind ourselves of the skills students need in this unpredictable world such as informed decision making, creative problem solving, and perhaps above all, adaptability (Tam Gloria et al., 2020).

Virtual classrooms are the closest equivalent of physical classrooms within the digital world. However, this mode of online teaching is, in no way, a substitute for traditional and conventional teaching (Sahni et al., 2020).

For those who do have access to the right technology, there is evidence that learning online can be more effective in a number of ways. Some research shows that on average, students retain $25-60 \%$ more material when learning online compared to only $8-10 \%$ in a classroom. This is mostly due to the students being able to learn faster online; e-learning requires $40-60 \%$ less time to learn than in a traditional classroom setting because students can learn at their own pace, going back and re-reading, skipping, or accelerating through concepts as they choose (Li Cathy et al., 2020). 


\section{Virtual Classroom}

A virtual classroom is a digital replica of traditional FACE-TO-FACE classroom where teachers teach and students learn in real-time face-to-face but via internet-enabled technology devices. Everything remains same in virtual classroom as traditional face toface classroom. The only difference is an online classroom uses technology to support teaching and learning. (Virtual Classroom software for live, 2020).

So, a virtual classroom is a web-based tool with an online whiteboard, breakout rooms, and screen sharing capabilities for teachers who want to conduct highly interactive live online teaching sessions.

\section{Virtual Classroom Technologies (MS Teams Features)}

In response to significant demand, many online learning platforms are offering free access to their online education services. To do so quickly and in a time of crisis, many vendors ramped up their global server infrastructure and engineering capabilities to ensure reliable connectivity. COVID-19 has become a catalyst for educational institutions worldwide to search for innovative solutions in a relatively short period of time. So, Tribhuvan University has selected online collaborative technology "Office 365 A1 Education, free online version of Office plus Microsoft Teams" for entire TU constituents and affiliated campuses ("Get Office 365 free," 2020).

Microsoft MS Teams virtual classroom was selected for its powerful range of tools, it flexible and attractive interface, and the ubiquity of the underlying technologies. MS Teams is a part of Microsoft 365 and when setup, creates: A new Microsoft 365 group, A SharePoint Online site and document library to store team files, An Exchange Online shared mailbox and calendar, A OneNote notebook ties into other Microsoft 365 and Office 365 apps such as Planner, Power BI etc.

Microsoft tailored the MS Teams to engage students with virtual face-to-face connections and activities, or set up a remote launch to keep classrooms connected and it's free for students and teachers with a valid school email address. MS Teams provides teachers to create "Virtual Classroom" with options tailored for teaching and learning and can expand those four walls and bring our students into a different type of interactive learning environment. With MS Teams we can continue to encourage and engage students from the walls of our "virtual classroom."

The MS Teams virtual classroom platform provides the following main benefits for Virtual Classroom (Ghioni et al., 2020). 
1. Holding Online Meetings in Teams (Share and collaborate in real-time): Microsoft Teams is a great platform to connect with students virtually and gives you as the teacher control of the meeting. You can speak and share video, mute and remove participants, share content and your screen, and privately view a PowerPoint presentation while participating in a live meeting. The organizer also has the option to start and stop recording of the meeting which allows for asynchronous learning by proving content to learners on their own time. Students can also share their screen and view PowerPoint presentations during meeting.

2. Conversations in Teams: While messaging technologies aren't anything new, there are some handy nuances and features in Microsoft Teams Chat and Channels. Can establish how you're trying to communicate i.e., a one-on-one chat, a small group chat that needs to happen privately, a public chat that other people might want to reference. Microsoft Teams has an option for each of these situations, and they're split between chat conversations and Channel conversations. When having a one-on-one chat, we can message, call, share the screen, and add other people to the conversation from a single interface. Separate from the Chat menu, Channels in Teams are places where larger groups can discuss, share pictures, collaborate on files, and so on.

3. Content and Collaboration in Teams (Store attachments within chats and channels): "You can't teach people everything they need to know. The best you can do is position them where they can find what they need to know and when they need to know it."Seymour Papert. That's the use of Content and Collaboration in MS Teams. MS Teams is an effective tool for communication between teachers and students. Teachers needs to understand-how communications \& files are managing in MS Teams? So, content can be shared in multiple ways when using Microsoft Teams. Teachers can add Tabs for apps within a channel to centralize where students are going and keeping the workflow in Teams. Teacher can also share content directly in channel posts with messages where can attach files and get options for uploading a copy, sharing a link, or other ways to share.

Collaborating in Teams with the integration of the OneNote class notebook, teachers can use OneNote notebooks in class or with students to take notes and collaborate. OneNote Class Notebooks have a personal workspace for every student, a Content Library for handouts, and a Collaboration Space for lessons and creative activities. OneNote (Class Notebook) is a digital notebook for the whole class to store text, images, handwritten notes, attachments, links, voice, video, and more. Each notebook is organized into three parts: 
Student Notebooks: A private space shared between the teacher and each individual student. Teachers can access every student notebook, while students can only see their own.

> Content Library: A read-only space where teachers can share handouts with students.

$>$ Collaboration Space: A space where everyone in your class can share, organize, and collaborate.

4. Creating Assignments \& Grading in Teams: Teachers have the ability to create assignments, customize each and every assignment to meet the needs of their students. Add grading rubrics for students to reference while working and for the teacher to use later when evaluating their work. Customize every assignment by adding or attaching resources. Teams lets the teacher create learning activities for students with integrated Office applications while also giving you the ability to leave feedback for students. Teacher can also grade and track student progress by using the Grades tab. They can view both upcoming and turned in assignments by class, or view them across all your classes. Selecting an assignment will allow you to turn it in or view feedback and scores.

5. Embed Forms \& Quiz in MS Teams: MS Teams has the feature of embedded Forms and Quizzes for students. This will let the teachers organize quizzes write inside teams along with their teaching material and can add a survey, create a poll using Teams Form.

6. Shorter, more Focused Group Work (Standard or Private Channels): Standard channels, which are what most channels are, are available to all team members in Teams. If teacher need a smaller, specific members for a particular group of students from large group, they can use a private channel. If any learning and teaching tasks or activities require students to work in groups, Standard or Private Channels can help for group work activities.

7. Access Teams Across all of Your Devices: Teams do not only have the comprehensive web interface, but available on both Android, Windows, and iOS. Teams provides a simple and easy-to-use app that allows you to chat with your team via text, have a voice conversation, or a video meeting.

8. Recording Storage: Microsoft Teams has the function of letting users record their meetings and group calls in Teams to capture audio, video, and screen sharing.

9. Teams New File Experience: Powered by SharePoint, the Teams file experience has now rolled out online to all tenants and can sync all MS Teams files to your PC or Mac. 
10. Cyber Security: Microsoft Teams is built with the best cyber security standards possible: ISO 27001 and SSAE16 SOC. There is also integrated mobile device management to help keep your data and fleet safe.

11. Integrate Third-party Applications Quickly: Microsoft Teams supports third party applications like Zendesk, which give you the functionality of integrating Teams into other areas of your business for streamlined processes and communication.

12. Collaborate Internally and Externally Securely: Security is yet another area where Microsoft Teams lifts itself above competitors. In fact, you can be confident in the cuttingedge security and compliance capabilities that come with your Office 365 subscription. Customise your teams to be private or publicly available for other users within your business who have been allocated an Office 365 account. With Microsoft Teams, you can enjoy advanced security controls that cover data-loss prevention, information barriers, retention policies, Discovery, legal hold, and more.

13. Direct Access to Email, Skype, One Drive, and SharePoint: Teams provides you with access to Office 365 applications within the one location, letting you work more efficiently. Access files and documents in One Drive and SharePoint, plus make calls and conduct video conferences directly from Teams.

14. Integrated between Outlook and Teams: The relationship between Teams and Outlook is seamless with the function of being able to move a Teams conversation to Outlook and Outlook to Teams including attachments.

15. Fully Integrated with Office 365: As another Microsoft product, Teams (of course!) integrates beautifully with Office 365 , which is perfect if you're already using that for your business. The Office 365 applications that get used every day in your workplace-like Word, Excel, PowerPoint, OneNote, SharePoint, and Outlook-are fully integrated into Microsoft Teams.

16. Manage App Catalogue: Admin can now manage apps straight from the Microsoft Teams admin centre via a "Manage Apps" page. This lets administrators view all of the available apps in the tenant, plus gives information to assist with decisions surrounding which apps would be best for their organisation.

\section{Pedagogy}

Pedagogy can be defined as the art of teaching. Pedagogy involves being able to convey knowledge and skills in ways that students can understand, remember and apply. Simply, 
Pedagogy is teaching, or more precisely the activity of educating or instructing, and the methods used to instruct. Pedagogy skills can generally be divided into classroom management skills and content-related skills (Pedagogical Skills, 2015).

Lecturers who are used to presenting face-to-face, teaching online classes through a virtual classroom interface proposes several new challenges and have to use new skills of pedagogy for virtual classroom.

\section{Results}

Students and teachers of Patan Multiple Campus used to deliver and access the BIT courses through virtual classroom platform using MS Teams. A total of 44 teachers and students involved in the online course delivery. Therefore, the 44-sample survey collected were analysed for this study. Out of 44 sample surveys, 36 were from students and 8 were from teachers. Three simple questions were asked to students and teachers to access acceptance level and how they conceive about virtual classroom in BIT online courses delivery.

The first question was asked to answer on a scale of 5=Excellent, $4=$ Very Good, $3=$ Good, $2=$ Fair and 1=Poor. BIT Students were attended 2-months face-to-face on-campus classes and 2-months virtual classroom and were asked to rate the acceptance level of Virtual classroom compared to on-campus traditional face-to-face classroom. Same teachers were also involved in delivering the BIT course both through traditional on-campus and Virtual Classroom. The results are summarised in Table 1.

Table 1: Accessing the level of acceptance of virtual classroom used in higher education compared to on-campus traditional face-to-face classroom

\begin{tabular}{|c|c|c|c|c|c|}
\hline $\begin{array}{c}\text { Total } \\
\text { Sample }\end{array}$ & Excellent & $\begin{array}{c}\text { Very } \\
\text { Good }\end{array}$ & Good & Fair & Poor \\
\hline 44 & 2 & 8 & 20 & 11 & 3 \\
\hline
\end{tabular}


Table-1 shows that all the teachers and students answered the 3 questions. Their answers are shown in Table-1 and Figure-1.

The second question was asked to measure the preference of education mode of learning and the results are summarised as in Table-2.

Similarly, student's and teacher's response on choice of education modes i.e., face-to-face traditional classroom, virtual classroom or Both (Blended) are shown in Table-2 and Figure-2.

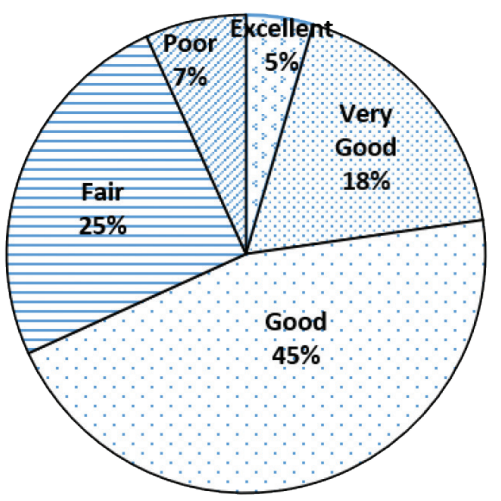

Table 2: Student's preference of education mode of learning

\begin{tabular}{|c|c|c|l|}
\hline $\begin{array}{l}\text { \% of respondent preferred } \\
\text { "Traditional on-campus } \\
\text { Face-to-Face classroom" }\end{array}$ & $\begin{array}{l}\text { \% of respondent } \\
\text { preferred "virtual } \\
\text { classroom" }\end{array}$ & $\begin{array}{l}\text { \% of respondent } \\
\text { preferred "Blended } \\
\text { learning" }\end{array}$ & Total \\
\hline $18 \%$ & $14 \%$ & $68 \%$ & $100 \%$ \\
\hline
\end{tabular}
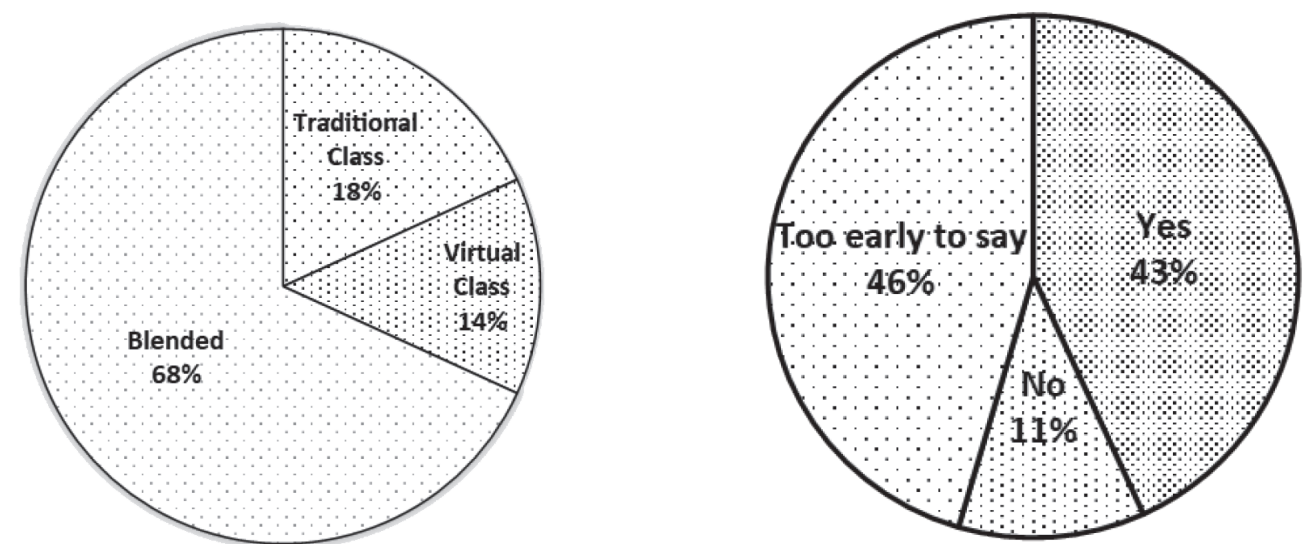

The third question was asked to measure their preference of virtual classroom for this technical course and the results are summarised in Table-3: 
Table 3: Student's preference of virtual classroom and their recommendation for enrolment in BIT-online virtual course.

\begin{tabular}{|c|c|c|}
\hline $\begin{array}{c}\% \text { of respondent } \\
\text { preferred "online } \\
\text { virtual classes" for } \\
\text { BIT program }\end{array}$ & $\begin{array}{c}\text { \% of respondent dislike } \\
\text { "online virtual classes" for } \\
\text { BIT program }\end{array}$ & $\begin{array}{c}\% \text { of respondent replied "Too early } \\
\text { to say" }\end{array}$ \\
\hline $43 \%$ & $11 \%$ & $46 \%$ \\
\hline
\end{tabular}

Student's and teacher's response for online virtual classes" of BIT program are shown in the Table-3: and Graph in Figure-3.

\section{Discussion}

This study focuses solely on students and teachers from Bachelor in Information Technology (BIT) program in delivering the BIT course content. Assessing the acceptance level on virtual classroom

Result 1: Accessing the level of acceptance of Virtual Classroom used in higher education compared to on-campus traditional FACE-TO-FACE classroom.

The first question was asked to rate the level of acceptance of virtual classroom compared to on-campus traditional Face-to-Face classroom. The students and Teachers response in the level of acceptance of Virtual Classroom is 58\% including excellent, very good and good as compared to $25 \%$ fair and $7 \%$ poor. So, online virtual classes are effective in the BIT course content delivery as compared to traditional Face-to-Face classroom. Only the student's and teacher's responses were measured to find the level of acceptance but there are many other factors which need to be studied further. According to a 12-year study conducted by SRI International, the pass rate of students that studied online was $9 \%$ higher than those who studied on campus in traditional classroom.

Result 2: Student's preference of education mode of learning

The second question was asked to measure the preference of education mode of learning. The blended learning means all the students attend the course either online or face-toface at a time and does not mean the students can choose either online or face-to-face and can attend classes as per their choices. The result showed that $68 \%$ of total respondent's preferred "Blended learning" while 18\% traditional face-to-face classroom and 14\% virtual classroom. So, students and teachers preference mode of education is blended. Research also shows that both modalities have been proven to be relatively effective but 
further researches are to be required to determine if one is truly better than the other. Though Virtual Classroom environment is more effective than face-to-face classroom but the topic of the lecture and course domain itself implies a different course delivery mode, more conductive to studying in a real working suitable environment.

Result 3: Student's preference of Virtual Classroom and their recommendation for enrolment in BIT-Virtual classroom course.

Regarding student's preference of Virtual Classroom and their recommendation for enrolment in BIT-Online virtual course, $46 \%$ responded "it is too early to say "and $43 \%$ responded "Yes" and 10\% with "No". So, research showed that students prefer "virtual classroom" but need to further check. As opposed to traditional face-to-face classroom, students have flexibility to attend the classes through a single Internet connection from any places and specifically in this COVID-19 pandemic.

\section{Conclusion}

This research work was to the acceptance level of virtual classroom and research shows that all the students and teachers have a good level of acceptance of the virtual classroom with 58 percent responded in the preference scales of excellent, very good and good. The results of this survey found that the virtual classroom has had accepted as an alternative mode of course delivery in higher education and preferred blended learning mode (i.e. both face-to-face and virtual classroom) on their learning activity. This result shows that Virtual classroom can be continued as an alternative mode of course delivery in TU. It should be noted that this study focused solely on students and teachers involved in one particular BIT classes and need to further research in other domain and in larger scale. Moreover, the results of this study serve as a backbone for the detail studies.

\section{References}

Aditya, B. R., \& Permadi, A. (2019). Assessing student acceptance of virtual classroom in higher education using the UTAUT. Journal of Physics Conference Series, 1254:012053. https://dx.doi.org/10.1088/1742-6596/1254/1/012053

Joe \& Kristin (2020). Creating a virtual classroom with Microsoft teams. https://www. themerrillsedu.com/blog-1/2020/4/25/creating-an-interactive-classroom-withmicrosoft-teams\#:

Get office 365 free for your entire school (2020). https://www.microsoft.com/en-us/ microsoft-365/academic/compare-office-365-education-plans?activetab=tab $\% 3 \mathrm{a}$ primaryr1 
Ghioni, A. (2020). The best 25 features of Microsoft teams in 2020. https://www. stanfieldit.com/microsoft-teams/

Li, C., \& Lalani, F. (2020). The world economic forum COVID action platform. The COVID-19 pandemic has changed education forever. https:/www.weforum.org/ agenda/2020/04/-coronavirus-education-global-covid19-online-digital-learning/

Madhu, B. (2015). Pedagogical skills. Mangalam College of Education. https://www. slideshare.net/bhav10ya/pedagogical-skills\#

Bower, M. (2014). Virtual classroom pedagogy. Macquarie University Sydney, NSW, Australia. https://www.researchgate.net/publication/221536761

Sahni, A. (2020). Indian educationist analyses online teaching \& its future. https:// www.scoonews.com/news/indian-educationist-analyses-online-teaching-itsfuture-9094

Tam, G., \& El-Azar, D. (2020). The world economic forum. 3-ways the coronavirus pandemic could reshape education. https://www.weforum.org/agenda/2020/03/3ways-coronavirus-is-reshaping-education-and-what-changes-might-be-here-to$\underline{\text { stayl }}$

Virtual classroom software for live interactive online classes (2020). What is a virtual classroom? https://www.wiziq.com/virtual-classroom/

Garrett, M. G. (2019). Padziwe online secondary school. https://slidetodoc.com/padziweonline-secondary-school-how-it-works-padziwe/ 